\title{
The effect of rumen digesta inoculation on the time course of recovery from classical diet-induced milk fat depression in dairy cows
}

\author{
D. E. Rico, ${ }^{1}$ Y. Ying, A. R. Clarke, ${ }^{2}$ and K. J. Harvatine ${ }^{3}$ \\ Department of Animal Science, Penn State University, University Park 16802
}

\begin{abstract}
Ten ruminally cannulated cows were used in a crossover design that investigated the effect of rumen digesta inoculation from non-milk fat-depressed cows on recovery from classical diet-induced milk fat depression (MFD) characterized by reduced fat yield, reduced de novo milk fat synthesis, and increased alternate trans isomers. Two additional cows fed a high-fiber and lowpolyunsaturated fatty acid (FA) diet $(31.8 \%$ neutral detergent fiber, $4.2 \% \mathrm{FA}$, and $1.2 \% \mathrm{C} 18: 2)$ were used as rumen digesta donors. Milk fat depression was induced during the first $10 \mathrm{~d}$ of each period by feeding a low-fiber and high-polyunsaturated FA diet (induction; $26.1 \%$ neutral detergent fiber, $5.8 \% \mathrm{FA}$, and $1.9 \%$ C18:2), resulting in a $30 \%$ decrease in milk fat yield. A recovery phase followed where all cows were switched to the high-forage, low-polyunsaturated FA diet and were allocated to (1) control (no inoculation) or (2) ruminal inoculation with donor cow digesta $(8 \mathrm{~kg} / \mathrm{d}$ for $6 \mathrm{~d}$ ). Milk yield and composition were measured every 3 d. Milk yield progressively decreased during recovery. Milk fat concentration increased progressively during the recovery phase and no effect of treatment existed at any time point. Also, no treatment effect of milk fat yield was detected. The concentration of milk de novo FA increased progressively during recovery for both treatments and was higher for inoculated compared with control cows on d 6. In agreement, milk fat concentration of trans-10,cis-12 conjugated linoleic acid decreased progressively in both treatments and was lower in inoculated cows on d 3 and 6 . Ruminal inoculation from non-milk fat-depressed cows did not change milk fat yield, but slightly accelerated the rate of recovery of de novo FA synthesis and normal ruminal FA biohydrogenation, demonstrating a possible oppor-
\end{abstract}

Received August 6, 2013.

Accepted March 6, 2014.

${ }^{1}$ Current address: 2425 Rue de l'Agriculture, Université Laval, Québec, QC G1V 0A6, Canada.

${ }^{2}$ Current address: NW 628 University of Pittsburg Medical Center Montefiore, Pittsburg, PA 15213.

${ }^{3}$ Corresponding author: kjh182@psu.edu tunity for other interventions that improve the ruminal environment to accelerate recovery from this condition. Key words: milk fat depression, ruminal inoculation, dairy cow

\section{INTRODUCTION}

Low fat syndrome in dairy cows, referred to as classical diet-induced milk fat depression (MFD), is characterized by a dramatic reduction in milk fat yield in response to highly fermentable diets and diets high in unsaturated FA (Bauman and Griinari, 2003). Although both de novo and preformed FA are decreased, a larger decrease in de novo synthesized FA occurs. In ruminants, the dietary factors that cause diet-induced MFD are associated with altered rumen fermentation and the production of unique bioactive FA from biohydrogenation (BH) of dietary PUFA. Dietary factors such as PUFA and diet fermentability affect both the extent of $\mathrm{BH}$ and the specific intermediates formed (Jenkins et al., 2008; Fuentes et al., 2009), presumably through modification of the microbial population of the rumen (Tajima et al., 2001; Weimer et al., 2010b). trans-10, cis-12 CLA is one of multiple BH intermediates known to inhibit milk fat synthesis in the mammary gland, and its mechanism of action involves the downregulation of genes related to FA uptake, transport, synthesis, and esterification in the mammary gland (Harvatine et al., 2009).

The mammary gland responds very rapidly to abomasal infusion of CLA, with maximal response and recovery occurring in 2 to $3 \mathrm{~d}$ (Baumgard et al., 2000). However, induction and recovery from MFD caused by highly fermentable and high-PUFA diets is much slower. For example, feeding a low-fiber and high-oil diet $(29.5 \% \mathrm{NDF}$ and $6.9 \% \mathrm{FA})$ to lactating dairy cows caused MFD in $9 \mathrm{~d}$, and milk fat yield was recovered in $15 \mathrm{~d}$ by feeding a higher fiber and lower fat ration (36.9\% NDF and 2.6\% FA; Rico and Harvatine, 2013). Interestingly, a 2-phase adaptation has been observed during induction and recovery of diet-induced MFD. During induction, cis-9,trans-11 CLA peaked on d 3 and then progressively decreased as trans-10, cis-12 CLA progressively increased, and during recovery, trans-10,cis-12 CLA progressively decreased and cis- 
9,trans-11 CLA initially increased before returning to baseline. The delayed onset of diet-induced MFD, the lag to peak concentrations of trans-FA associated with $\mathrm{MFD}$, and the secondary rise of the normal $\mathrm{BH}$ isomers during recovery suggests that ruminal adaptation has a greater effect on the time course compared with substrate for $\mathrm{BH}$.

Satter and Bringe (1969) switched lactating cows between a high- and a low-forage diet, with or without a simultaneous near-total rumen content exchange from cows fed the same diet, and observed that both induction of and recovery from MFD were accelerated by rumen exchange relative to diet switch alone. This suggests that adaptation of the rumen environment or the microbial population is a key limiting factor. Furthermore, Weimer et al. (2010b) reported extensive shifts in ruminal bacteria communities during dietinduced MFD. Lastly, fecal microbiota transplants are increasingly used for treatment of several disorders in humans, with astounding results (Borody and Khoruts, 2012). Our objective was to test the effect of ruminal inoculation from a non-milk fat-depressed cow on the rate of recovery from classical diet-induced MFD after a diet switch. We hypothesized that the recovery of normal BH intermediates and milk fat synthesis would be accelerated by inoculation with ruminal microflora from a non-milk fat-depressed cow.

\section{MATERIALS AND METHODS}

\section{Experimental Design and Treatments}

All experimental procedures were approved by the Pennsylvania State University Institutional Animal Care and Use Committee (University Park). Twelve ruminally cannulated Holstein cows were housed in tie-stalls at the Pennsylvania State University Dairy Production Research and Teaching Center. Ten cows $(197 \pm 94 \mathrm{DIM} ; 41 \pm 9.8 \mathrm{~kg}$ milk$/ \mathrm{d}$; mean $\pm \mathrm{SD})$ were randomly assigned to treatment sequences in a crossover design with 28-d periods, and balanced for residual effects. Two additional cows $(195 \pm 79$ DIM; $39 \pm 9.8$ $\mathrm{kg}$ milk/d; mean $\pm \mathrm{SD}$ ) fed a high-fiber, low-PUFA diet (31.8\% NDF, $4.2 \%$ total FA, and 1.2\% C18:2; Table 1) were used as rumen digesta donors. A total of $20 \mathrm{~kg} / \mathrm{d}$ (as-is basis) were removed from each donor cow during the inoculation period. This is equivalent to approximately $25 \%$ of the expected rumen digesta pool (Oba and Allen, 2003; Harvatine and Allen, 2006). Each experimental period was $28 \mathrm{~d}$ in length and included a 10-d MFD induction and 18-d MFD recovery phase. Cows were milked twice per day at 0500 and $1700 \mathrm{~h}$ and received recombinant bST every $14 \mathrm{~d}$ (Posilac; Elanco Animal Health, Greenfield, IN).
Table 1. Ingredients and chemical composition of diets

\begin{tabular}{|c|c|c|}
\hline \multirow[b]{2}{*}{ Item } & \multicolumn{2}{|c|}{$\operatorname{Diet}^{1}$} \\
\hline & Induction & Recovery \\
\hline \multicolumn{3}{|l|}{ Ingredient, $\mathrm{g} / 100$ of $\mathrm{DM}$} \\
\hline Corn silage & 36.8 & 37.0 \\
\hline Alfalfa haylage $^{3}$ & 6.6 & 17.3 \\
\hline Ground corn & 17.4 & 9.2 \\
\hline Roasted soybeans & 9.7 & 5.2 \\
\hline Canola meal & 9.5 & 9.4 \\
\hline Cookie meal & 5.3 & 5.8 \\
\hline Grass hay/straw ${ }^{4}$ & 3.7 & 5.4 \\
\hline Sugar cane molasses & 2.6 & 2.3 \\
\hline Soybean oil & 1.6 & - \\
\hline Optigen $^{5}$ & 0.5 & 0.5 \\
\hline Cottonseed hulls & 3.8 & 5.4 \\
\hline Mineral and vitamin $\operatorname{mix}^{6}$ & 2.7 & 2.5 \\
\hline \multicolumn{3}{|c|}{ Chemical composition, ${ }^{7} \mathrm{~g} / 100 \mathrm{~g}$ of DM } \\
\hline $\mathrm{CP}$ & 16.9 & 16.9 \\
\hline NDF & 26.1 & 31.8 \\
\hline $\mathrm{ADF}$ & 15.5 & 20.8 \\
\hline Starch & 28.1 & 23.0 \\
\hline Total FA & 5.8 & 4.2 \\
\hline C18:1n-9 & 1.4 & 0.9 \\
\hline C18:2n-6 & 1.9 & 1.2 \\
\hline C18:3n-3 & 0.3 & 0.3 \\
\hline$\Sigma$ Unsaturated FA & 3.8 & 2.6 \\
\hline
\end{tabular}

${ }^{1}$ Induction is a low-fiber and high-PUFA diet fed during the induction phase of each period, and recovery is a high-forage and low-PUFA diet fed during the recovery phase of each period.

${ }^{2}$ Contained $37 \% \mathrm{DM}, 8.4 \% \mathrm{CP}$, and $37.2 \% \mathrm{NDF}$.

${ }^{3}$ Contained $36.3 \%$ DM, $21.45 \% \mathrm{CP}$, and $39.9 \% \mathrm{NDF}$.

${ }^{4}$ Contained $89 \% \mathrm{DM}, 7.6 \% \mathrm{CP}$, and $71.2 \% \mathrm{NDF}$.

${ }^{5}$ Optigen is an NPN source $(256 \%$ CP, DM basis; Alltech Inc., Lexington, $\mathrm{KY}$ ).

${ }^{6}$ Composition (DM basis): $11 \%$ CP, $18 \%$ NDF, $5.2 \%$ fat, $14.9 \% \mathrm{Ca}$, $0.35 \% \mathrm{P}, 4.58 \% \mathrm{Mg}, 0.41 \% \mathrm{~K}, 0.31 \% \mathrm{~S}, 357 \mathrm{mg}$ of $\mathrm{Cu} / \mathrm{kg}, 1,085 \mathrm{mg}$ of $\mathrm{Zn} / \mathrm{kg}, 181 \mathrm{mg}$ of $\mathrm{Fe} / \mathrm{kg}, 6.67 \mathrm{mg}$ of $\mathrm{Se} / \mathrm{kg}, 262,105 \mathrm{IU}$ of vitamin A/ $\mathrm{kg}, 65,421 \mathrm{IU}$ of vitamin $\mathrm{D} / \mathrm{kg}$, and $1,970 \mathrm{IU} / \mathrm{kg}$ of vitamin $\mathrm{E}$ (Cargill Animal Nutrition, Roaring Spring, PA).

${ }^{7}$ Crude protein, NDF, ADF, and starch were analyzed by Cumberland Valley Analytical Services (Maugansville, MD; $\mathrm{n}=2$ per diet).

During the MFD induction phase $(10 \mathrm{~d})$ all cows were fed a low-fiber, high-PUFA diet (Table 1; Supplemental Table S1; http://dx.doi.org/10.3168/jds.20137342). During the subsequent MFD recovery phase, cows were fed a high-fiber, low-PUFA diet (recovery), with or without ruminal digesta inoculation. Rumen digesta inoculation included removal of $8 \mathrm{~kg}$ of digesta at $1300 \mathrm{~h}$ on $\mathrm{d} 1$ to 6 and replacement with digesta from non-milk fat-depressed donor cows. Similarly, for control cows, $8 \mathrm{~kg}$ of rumen contents were evacuated and returned on the same days. The high-forage, lowPUFA diet was also fed during a 7-d washout between experimental periods.

Cows were fed once daily $(0800 \mathrm{~h})$ at $110 \%$ of expected intake. Forage and diet DM contents were determined weekly for diet adjustment and DMI determination (forced-air oven at $55^{\circ} \mathrm{C}$ for $72 \mathrm{~h}$ ). All individual feed ingredients were sampled weekly and stored at 
$-20^{\circ} \mathrm{C}$, thawed at room temperature, and DM content determined similarly. Individual feeds were ground in a Wiley mill through a 1-mm screen (Arthur H. Thomas Co., Philadelphia, PA). Samples of all ingredients were composited by period and individual forages and a representative mixture of concentrate feeds were analyzed for nutrient composition by wet chemistry procedures (Cumberland Valley Analytical Services Inc., Maugansville, MD). Briefly, assays conducted were DM and CP according to AOAC International (2000); NDF and ADF according to Van Soest et al. (1991), using heatstable amylase and sodium sulfite; and starch according to Hall (2009). Total FA concentration and FA profile of the TMR was determined by gas chromatography after direct methylation (Sukhija and Palmquist, 1988).

\section{Milk Sampling and Analysis}

The time course of recovery from MFD was observed by collection of milk samples every third day during the recovery phase of each period. One subsample was stored at $4^{\circ} \mathrm{C}$ with liquid preservative (BronolabWII; Dairy One Coop. Inc., State College, PA) until analyzed for fat and protein by infrared spectroscopy [Fossomatic 4000 MilkoScan and 400 Fossomatic (Foss Electric A/S, Hillerød, Denmark); AOAC International, 2000; method 972.160; Dairy One Coop. Inc.]. A second subsample was stored at $-20^{\circ} \mathrm{C}$ without preservative until analyzed for FA composition.

Milk FA analysis was performed as described by Rico and Harvatine (2013). Briefly, milk fat was composited by day based on milk fat yield at each milking, and lipids were extracted with hexane:isopropanol, and transmethylated in the presence of sodium methoxide. Quantification of FAME was performed by gas chromatography using a fused-silica capillary column (SP$2560 ; 100 \mathrm{~m} \times 0.25$-mm i.d. with $0.2-\mu \mathrm{m}$ film thickness; Sigma-Aldrich, St. Louis, MO) and a flame ionization detector with hydrogen as the carrier gas. Milk FA yields are reported as NEFA as described by Rico and Harvatine (2013).

\section{Statistical Analysis}

Data were statistically analyzed as a crossover design using PROC MIXED of SAS with repeated measures (version 9.3; SAS Institute Inc., Cary, NC). The model was $\mathrm{Y}_{\mathrm{ijklmn}}=\mu+\mathrm{S}_{\mathrm{i}}+\mathrm{P}_{\mathrm{j}}+\mathrm{C}_{\mathrm{k}}\left(\mathrm{S}_{\mathrm{i}}\right)+\mathrm{X}_{\mathrm{l}}+\mathrm{T}_{\mathrm{m}}+\mathrm{D}_{\mathrm{n}}$ $+T_{m} \times D_{n}+e_{i j k l m n}$, where $Y_{i j k l m n}$ is the variable of interest, $\mu$ is the overall mean, $\mathrm{S}_{\mathrm{i}}$ is the random effect of sequence ( $\mathrm{i}=1$ to 2 ), $\mathrm{P}_{\mathrm{j}}$ is the random effect of period ( $\mathrm{j}=1$ to 2$), \mathrm{C}_{\mathrm{k}}\left(\mathrm{S}_{\mathrm{i}}\right)$ is the random effect of cow nested in sequence $(\mathrm{k}=1$ to 10$), \mathrm{X}_{1}$ is the fixed effect of $\mathrm{d} 0$ of the recovery phase as a covariate, $T_{m}$ is the fixed effect of treatment ( $m=1$ to 2$), D_{n}$ is the fixed effect of time ( $\mathrm{n}=1$ to 4$), \mathrm{T}_{\mathrm{m}} \times \mathrm{D}_{\mathrm{n}}$ is the interaction of treatment and time, and $\mathrm{e}_{\mathrm{ijklmn}}$ is the residual error. Time was the repeated variable and cow by period was the subject. The ARH(1) or AR(1) covariance structures were used, based on the Akaike and Bayesian information criteria. The Kenward-Rogers denominator degrees of freedom adjustment was used. The preplanned contrast tested the effect of inoculation at each time point.

Data for some variables were logarithmically transformed when appropriate and back-transformed data are reported. Data points with studentized residuals outside of \pm 3.0 were considered outliers and excluded from analysis, which typically included less than 3 data points per variable. Cow periods that did not result in MFD induction (less than a 15\% decrease in milk fat concentration) were excluded from the analysis. This reduction in milk fat concentration was successfully achieved in 8 cows in period 1 and 6 cows in period 2 .

\section{RESULTS}

\section{Induction of MFD}

The induction diet successfully reduced milk fat concentration and yield in both periods (Table 2). The induction diet reduced milk fat yield by $29 \%$ and milk fat concentration by $30 \%$, whereas milk yield and milk protein yield and concentration were not changed.

\section{DMI and Milk Production and Composition}

No effect of treatment or treatment by time interaction was detected for DMI or milk yield $[26.8 \pm 1.27$ and $33.8 \pm 1.86 \mathrm{~kg} / \mathrm{d}$ (mean $\pm \mathrm{SEM})$, respectively; Table 3$]$. An effect of time on milk yield was detected, with both treatments progressively decreasing during the recovery phase; however, the biggest reduction occurred between d 0 and $3(5.0 \mathrm{~kg} / \mathrm{d}$ average reduction; Figure 1). Milk protein concentration and yield were not affected by rumen inoculation, but milk protein yield decreased over time (Table 3; Supplemental Figure S1; http://dx.doi. org/10.3168/jds.2013-7342).

Milk fat concentration increased progressively after switching to the recovery diet; however, no difference existed between treatments at any time point (Figure 1). In contrast, milk fat yield remained constant during recovery and no effect of treatment existed at any time point (Figure 1). No treatment or treatment by time interaction was detected for the yield of milk de novo or preformed FA $(<16 \mathrm{C}$ and $>16 \mathrm{C}$, respectively; Supplemental Figure S2; http://dx.doi.org/10.3168/ jds.2013-7342). An effect of time on the yield of de novo FA $(P<0.001)$ was detected, where yield of de 
Table 2. Effect of ruminal inoculation on DMI and milk yield and composition during induction of dietinduced milk fat depression

\begin{tabular}{|c|c|c|c|c|c|}
\hline \multirow[b]{2}{*}{ Item } & \multicolumn{3}{|c|}{ Day in induction ${ }^{1}$} & \multirow[b]{2}{*}{$\mathrm{SE}$} & \multirow[b]{2}{*}{$P$-value ${ }^{2}$} \\
\hline & $\mathrm{d} 0$ & d 7 & d 10 & & \\
\hline \multicolumn{6}{|c|}{ Milk yield, $\mathrm{kg} / \mathrm{d}$} \\
\hline Milk & 39.72 & 40.68 & 40.42 & 2.62 & 0.92 \\
\hline Fat & 1.62 & 1.24 & 1.15 & 0.17 & $<0.001$ \\
\hline Protein & 1.25 & 1.27 & 1.27 & 0.1 & 0.95 \\
\hline \multicolumn{6}{|c|}{ Milk composition, \% } \\
\hline Fat & 4.03 & 3.02 & 2.83 & 0.41 & $<0.001$ \\
\hline Protein & 3.08 & 3.07 & 3.11 & 0.10 & 0.63 \\
\hline
\end{tabular}

${ }^{1}$ Milk fat depression was induced by feeding a low-fiber and high-unsaturated-fat diet. Samples were taken the day before the diet and after 7 and $10 \mathrm{~d}$.

${ }^{2}$ Main effect of day of the induction period.

novo FA increased progressively, but was not different between treatments at any time point during recovery from MFD (Supplemental Figure S2).

\section{Milk FA Profile and $\Delta^{9}$-Desaturase Indices}

An effect of time was detected, but no effect of treatment or treatment by time interaction on milk fat concentration of de novo $(<16 \mathrm{C}), 16-\mathrm{C}$, and preformed FA $(>16 \mathrm{C}$; Table 4$)$. In both treatments, the proportion of de novo and 16-C FA increased progressively, whereas the proportion of preformed FA decreased progressively during recovery from MFD (Figure 2). However, the concentration of de novo synthesized FA was increased $11 \%$ by inoculation on the last day of digesta switching (d 6; Figure 2A; $P<0.01$ ).

Milk fat concentrations of trans-10 C18:1 and trans10, cis-12 CLA, intermediates of the alternative pathway of ruminal $\mathrm{BH}$, decreased progressively during recovery (Figure 3A and 3B) and a treatment by time interaction was detected for both FA $(P<0.05$; Table 4). Inoculation decreased trans-10 C18:1 by $44 \%$ compared with the control on the last day of digesta switching (d 6; $P<0.01$ ), whereas it reduced trans-10, cis-12 CLA on $\mathrm{d} 3$ and 6 by over $50 \%(P<0.05)$.

A treatment by time interaction was detected for milk fat concentration of trans-11 C18:1 $(P=0.03)$ and a tendency for a treatment by time interaction for $\mathrm{cis}^{-}$ 9,trans-11 CLA ( $P=0.07$; Table 4$)$, which are intermediates of the normal pathway of ruminal $\mathrm{BH}$. In agreement with the decreased utilization of the alternate $\mathrm{BH}$ pathway, trans-11 C18:1 tended to be increased $(P=$ 0.09) and cis-9,trans-11 CLA was increased by inoculation on d $6(P=0.02)$. Additionally, trans-11 C18:1 tended to be decreased on d $9(P=0.05)$ and was decreased on d 12 by $31 \%(P=0.04$; Figure $3 \mathrm{C})$. The

Table 3. Effect of ruminal inoculation on DMI and milk yield and composition during recovery from dietinduced milk fat depression

\begin{tabular}{|c|c|c|c|c|c|c|}
\hline \multirow[b]{2}{*}{ Item } & \multicolumn{2}{|c|}{ Treatment $^{1}$} & \multirow[b]{2}{*}{ SEM } & \multicolumn{3}{|c|}{$P$-value ${ }^{2}$} \\
\hline & Control & INOC & & Trt & Time & Trt $\times$ time \\
\hline & 26.7 & 26.9 & 1.3 & 0.93 & 0.02 & 0.89 \\
\hline \multicolumn{7}{|l|}{ Milk yield, $\mathrm{kg} / \mathrm{d}$} \\
\hline Milk & 35.7 & 31.9 & 1.90 & 0.16 & $<0.001$ & 0.91 \\
\hline Fat & 1.29 & 1.09 & 0.10 & 0.18 & 0.70 & 0.68 \\
\hline Protein & 1.14 & 1.04 & 0.05 & 0.21 & $<0.001$ & 0.87 \\
\hline \multicolumn{7}{|l|}{ Milk composition, \% } \\
\hline Fat & 3.52 & 3.56 & 0.15 & 0.85 & $<0.01$ & 0.76 \\
\hline Protein & 3.20 & 3.28 & 0.04 & 0.21 & 0.41 & 0.87 \\
\hline \multicolumn{7}{|l|}{ Milk FA by source, ${ }^{3} \mathrm{~g} / \mathrm{d}$} \\
\hline$<16 \mathrm{C}$ & 270 & 271 & 39 & 0.99 & $<0.001$ & 0.71 \\
\hline$>16 \mathrm{C}$ & 458 & 465 & 50 & 0.61 & 0.17 & 0.68 \\
\hline
\end{tabular}

${ }^{1}$ Control $=$ no inoculation; INOC $=$ ruminal inoculation with $8 \mathrm{~kg}$ of donor cow digesta $/ \mathrm{d}$ from $\mathrm{d} 1$ to 6 during recovery from diet-induced milk fat depression.

${ }^{2}$ Trt $=$ treatment effect; time $=$ effect of day in recovery from milk fat depression.

${ }^{3}$ Fatty acids $<16 \mathrm{C}$ originate from de novo synthesis in the mammary gland and FA $>16 \mathrm{C}$ originate from plasma. 

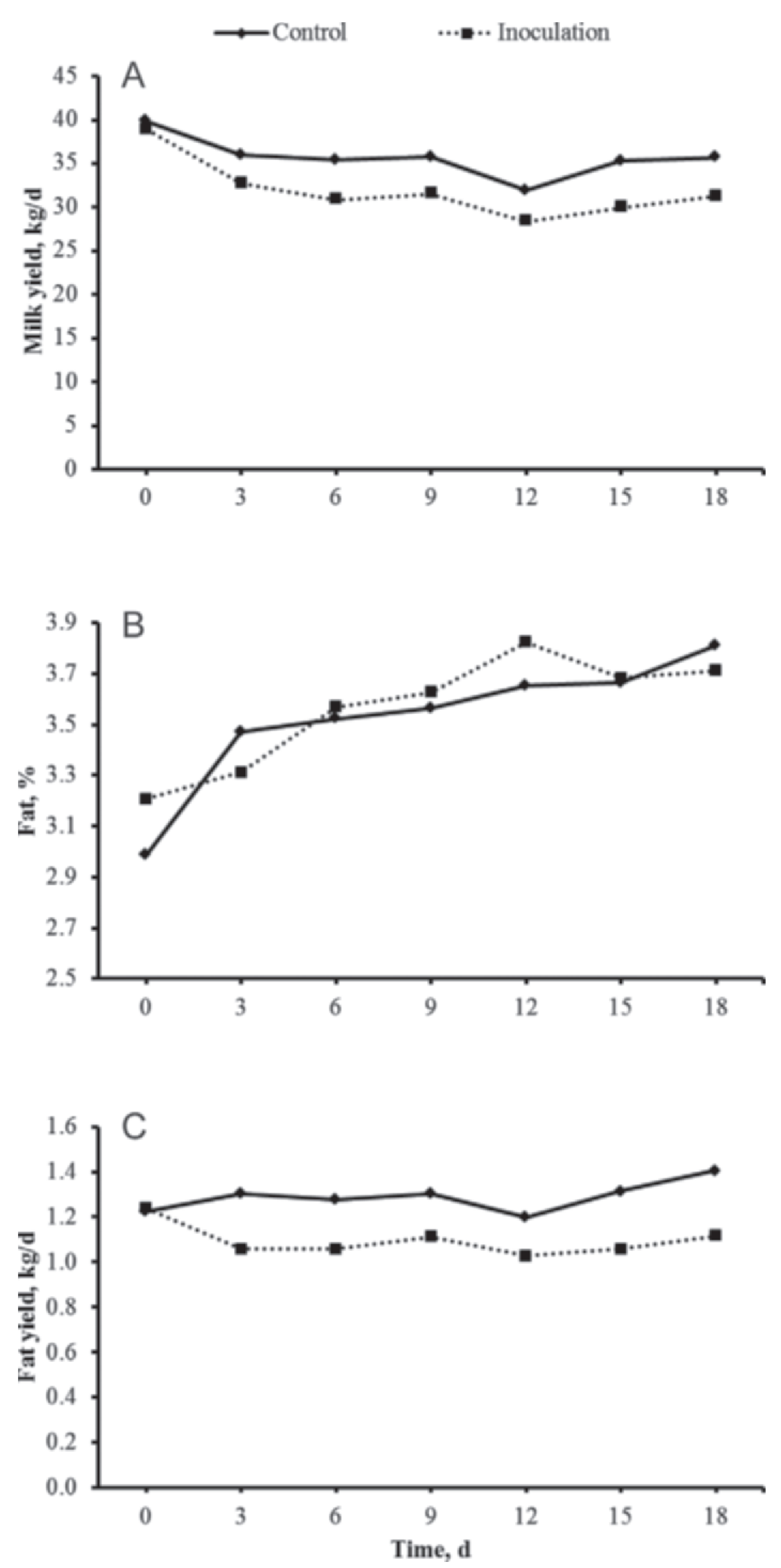

Figure 1. Effect of daily ruminal inoculation (from d 1 to 6 ) with digesta from non-milk fat-depressed cows (inoculation) on milk yield and milk fat concentration and yield during recovery from diet-induced milk fat depression compared with the control. (A) Milk yield; (B) milk fat concentration; (C) milk fat yield. Treatments did not differ at any time point $(P>0.10)$. Standard error of the mean $=1.9$, 0.15 , and 0.10 , for milk yield, milk fat concentration, and milk fat yield, respectively. cis-9,trans-11 CLA concentration decreased progressively in both treatments, although it was increased by inoculation on d $6(37 \% ; P=0.02$; Figure $3 \mathrm{D})$.

No effect of treatment $(P>0.7)$ or treatment by time interaction $(P>0.5)$ was detected for $\mathrm{C} 14$ and C16 desaturase indices, although an effect of time $(P$ $<0.01$; Table 4) was detected. Both indices decreased progressively and reached a nadir on d 12 of recovery from MFD. Treatments had no effect on the desaturase indices at any time point (data not shown).

\section{DISCUSSION}

The production of bioactive FA by rumen microbes during MFD is dependent on the rumen environment, amount of PUFA substrate available for $\mathrm{BH}$, and the rumen microbial population (Jenkins et al., 2008). Importantly, these factors have multiple complex interactions. The substrate entering the rumen was immediately changed during the recovery period, but the composition of rumen digesta and the rumen environment had a slightly longer lag. However, we have observed increased rumen $\mathrm{pH}$ by d 3 of recovery in other similar experiments (unpublished data). The ruminal inoculation treatment used in the current experiment was intended to reintroduce a normal rumen microbiota and determine if reestablishment of normal $\mathrm{BH}$ pathways and capacity and recovery from MFD could be accelerated.

Rumen probiotic treatments can be achieved through feeding specific exogenously cultivated microbial species (Francisco et al., 2002; Chiquette et al., 2008; Aikman et al., 2011) or transfer of rumen digesta or fluid. Rumen digesta transfer was selected for the current experiment because it is expected that many species are important for the establishment of normal $\mathrm{BH}$, and the most important species for this process in vivo are not well established. Cole (1991) investigated the effect of transferring approximately half of the rumen contents between fed and fasted sheep and observed little effect of digesta on DMI, feeding behavior, and rumen function, thus concluding that postabsorptive mechanisms predominated. However, rumen digesta inoculation $(300 \mathrm{~g} / \mathrm{d})$ from sheep fed plants containing toxic tannins (Acacia angustissima) provided protection to nonadapted sheep (Saarisalo et al., 1999). Additionally, near complete exchange of ruminal digesta was investigated in dairy cows (Satter and Bringe, 1969; Weimer et al., 2010a), but did not provide an assessment of the modification of the microbial community or a dissection of the effect of digesta composition from the microbial community. In contrast, the intent of the present experiment was to specifically study the response to inoculation with a microbial community as- 
Table 4. Effect of ruminal inoculation on milk FA composition during recovery from diet-induced milk fat depression

\begin{tabular}{|c|c|c|c|c|c|c|}
\hline \multirow[b]{2}{*}{ FA, $\%$ of total FA } & \multicolumn{2}{|c|}{ Treatment $^{1}$} & \multirow[b]{2}{*}{$\mathrm{SE}$} & \multicolumn{3}{|c|}{$P$-value ${ }^{2}$} \\
\hline & Control & INOC & & Trt & Time & Trt $\times$ time \\
\hline trans-10 C18:1 & 1.08 & 0.92 & 0.10 & 0.03 & $<0.001$ & 0.04 \\
\hline trans-11 C18:1 & 1.10 & 0.99 & 0.08 & 0.33 & $<0.001$ & 0.03 \\
\hline cis-9,trans-11 CLA & 0.66 & 0.67 & 0.043 & 0.85 & $<0.001$ & 0.07 \\
\hline trans-10,cis-12 CLA & 0.010 & 0.008 & 0.001 & 0.07 & $<0.001$ & 0.05 \\
\hline $\mathrm{FA}<16 \mathrm{C}^{3}$ & 23.1 & 23.6 & 0.35 & 0.17 & $<0.001$ & 0.35 \\
\hline $\mathrm{FA}>16 \mathrm{C}$ & 42.8 & 41.9 & 1.40 & 0.07 & $<0.001$ & 0.86 \\
\hline 16-C FA & 26.1 & 27.2 & 0.76 & 0.27 & 0.01 & 0.82 \\
\hline C14 desaturase index ${ }^{4}$ & 0.10 & 0.11 & 0.01 & 0.39 & $<0.001$ & 0.38 \\
\hline C16 desaturase index & 0.05 & 0.06 & 0.01 & 0.59 & $<0.001$ & 0.91 \\
\hline
\end{tabular}

${ }^{1}$ Control $=$ no inoculation; INOC $=$ ruminal inoculation with $8 \mathrm{~kg}$ of donor cow digesta $/ \mathrm{d}$ from $\mathrm{d} 1$ to 6 during recovery from diet-induced milk fat depression.

${ }^{2}$ Trt $=$ treatment effect; time $=$ effect of day in recovery from milk fat depression.

${ }^{3}$ Fatty acids $<16 \mathrm{C}$ originate from de novo synthesis in the mammary gland, $>16$-C FA originate from plasma, and 16-C FA originate from both sources.

${ }^{4} \mathrm{C} 14$ desaturase index $=\mathrm{C} 14: 1 /(\mathrm{C} 14: 1+\mathrm{C} 14: 0) ; \mathrm{C} 16$ desaturase index $=\mathrm{C} 16: 1 /(\mathrm{C} 16: 1+\mathrm{C} 16: 0)$.

sociated with normal ruminal BH. The amount of inoculum transferred $(8 \mathrm{~kg} / \mathrm{d})$ in the current experiment is approximately $10 \%$ of whole-rumen digesta (as-is basis; Oba and Allen, 2003; Harvatine and Allen, 2006). An effective dose is difficult to predict, but the level was selected to provide a feasible, but substantial transfer, while maintaining the endogenous rumen environment and minimizing disruption of rumen digesta donors.

The time course of diet-induced MFD induction and recovery were previously described by Rico and Harvatine (2013) using similar diets, and provided the basis for the length of the induction and recovery phases of the current experiment. Specifically, near-complete MFD induction occurred by approximately $10 \mathrm{~d}$ using a similar high-corn silage, low-fiber, and high-PUFA diet. Importantly, the experimental design did not require reaching a maximal reduction. However, milk fat must be decreased to allow examination of recovery. Cow periods that failed to decrease milk fat concentration more than $15 \%$ were removed. The recovery diet was designed to allow recovery from diet-induced MFD, as it was higher in NDF and lower in PUFA content than the induction diet.

A previous time-course experiment observed that milk fat concentration and yield progressively increased and were completely recovered in $15 \mathrm{~d}$ when cows were fed a moderate-NDF and low-PUFA diet following MFD induction (Rico and Harvatine, 2013). In the current experiment, milk fat percentage progressively increased and plateaued near d 15 and was not affected by inoculation treatments at any time point (Figure 1). Milk fat yield was not changed during recovery. The recovery diet resulted in a substantial loss of milk yield, presumably due to the lower fermentability of the recovery diet. Decreasing diet fermentability will commonly decrease milk production and it appears that this occurred in the recovery diet. This general decrease in milk production makes interpretation of recovery of milk fat yield difficult. However, the milk FA profile shows recovery from classical diet-induced MFD. Specifically, MFD is characterized by a larger reduction in de novo synthesized $\mathrm{FA}$, which results in a decrease in the proportion of FA less than $16 \mathrm{C}$ and an increase in the concentration of the intermediates of the alternative $\mathrm{BH}$ pathway (e.g., trans-10, cis-12 CLA). The progressive changes in the proportion of de novo and preformed FA and the rapid decrease in alternative $\mathrm{BH}$ intermediates indicates recovery from classical diet-induced MFD, even though milk fat yield was not increased over time. A further increase in milk fat or recovery of the normal milk FA profile may have been achievable beyond d 18 in the current experiment; however, the hypothesis is based on the rate of recovery after diet modification and the effect of short-term inoculation. Importantly, the inoculation treatment accelerated the recovery of the proportion of de novo synthesized FA on d 6 and appeared to shift the recovery of de novo synthesized FA by approximately $3 \mathrm{~d}$. The inoculation treatment was terminated on d 6 and did not appear to have any carryover effect on de novo milk fat synthesis; however, there was little room for additional recovery.

Others have reported differing effects of probiotic treatments on milk fat in dairy cows. Milk fat concentration tended to increase when transition dairy cows where ruminally infused with a daily dose of $2 \times 10^{11}$ cells of Prevotella bryantii (25A), whereas no effects were observed on DMI or milk yield (Chiquette et al., 2008). In contrast, administration of a propionibacteria culture top-dress $(17 \mathrm{~g} / \mathrm{d})$ decreased DMI, but had no 

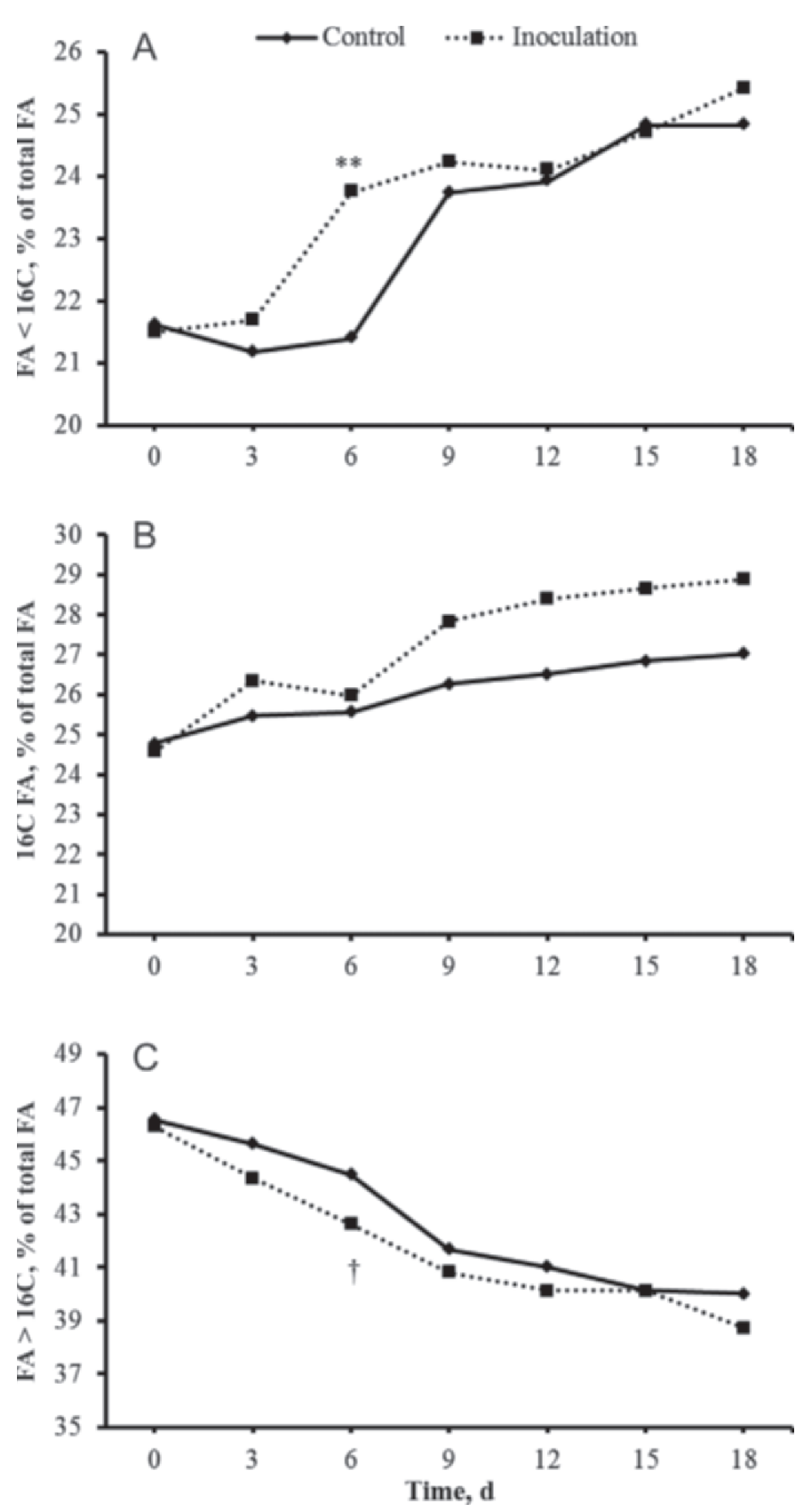

Figure 2. Effect of daily ruminal inoculation (from d 1 to 6 ) with digesta from non-milk fat-depressed cows (inoculation) on the concentration of milk FA by source during recovery from diet-induced milk fat depression compared with the control. (A) De novo FA; (B) 16-C FA; (C) preformed FA. Preplanned contrasts tested the difference between the control and inoculation at each time point. ${ }^{* *} P<0.01 ; \dagger P$ $<0.1 ;$ SEM $=0.35,0.76$, and 1.40, for de novo, $16-\mathrm{C}$, and preformed FA, respectively.

effect on milk yield or milk fat concentration in earlylactation cows (Francisco et al., 2002). The ability to develop probiotic treatments depends on the identification of specific microbial species with important functional roles in $\mathrm{BH}$ that grow competitively under conditions of milk fat-challenging diets.

A 2-phase response has been previously reported for milk fat trans FA during recovery (Rico and Harvatine, 2013). During the first phase, from approximately d 1 to 10 of recovery, milk fat trans-10 C18:1 and trans10,cis-12 CLA concentrations decrease and during the second phase, trans-11 C18:1 and cis-9,trans-11 CLA concentrations increase slightly before returning to a nadir. In the current experiment, inoculation decreased the utilization of the alternate pathway as evidenced by decreased milk fat trans-10 C18:1 and trans-10, cis-12 CLA concentrations during the first phase (d 6). In agreement, a greater use of the normal $\mathrm{BH}$ pathway was observed during this phase as milk fat concentration of trans-11 C18:1 and cis-9,trans-11 CLA concentrations increased. Additionally, inoculation appears to have increased the capacity of the normal $\mathrm{BH}$ pathway during the second phase of recovery as the normal $\mathrm{BH}$ pathway isomers are decreased on $\mathrm{d} 9$ and 12 . The increased concentration of de novo synthesized FA, taken together with the changes in trans $\mathrm{FA}$ isomers during the first and second phases of recovery, demonstrate a slight acceleration of recovery from classical diet-induced MFD by the ruminal digesta inoculation. Recently, fecal microbiota transplants from healthy donors that provide complete and stable microbial communities have resulted in improved recovery from Clostridium difficile infections and restored normal bowel function in human subjects (Borody and Khoruts, 2012), demonstrating the effectiveness of a similar approach.

Milk fat desaturase indexes are commonly used as a proxy of the activity of stearoyl-CoA desaturase enzyme (Perfield et al., 2006; Harvatine et al., 2009). In the present experiment, the $\mathrm{C} 14$ and $\mathrm{C} 16$ desaturase indexes progressively decreased during recovery from MFD, in agreement with the progressive decrease in both $\mathrm{C} 14$ and $\mathrm{C} 16$ desaturase indexes during recovery from diet-induced MFD reported by Rico and Harvatine (2013).

\section{CONCLUSIONS}

Milk fat yield was not changed, but the recovery of the concentration of de novo synthesized FA and normal ruminal $\mathrm{BH}$ pathways were slightly accelerated by ruminal inoculation with digesta from non-milkfat-depressed cows. The mechanism likely involves the restoration of normal microbial populations that have a higher capacity for BH of PUFA and utilize $\mathrm{BH}$ pathways that do not produce milk fat-depressing intermediates. 

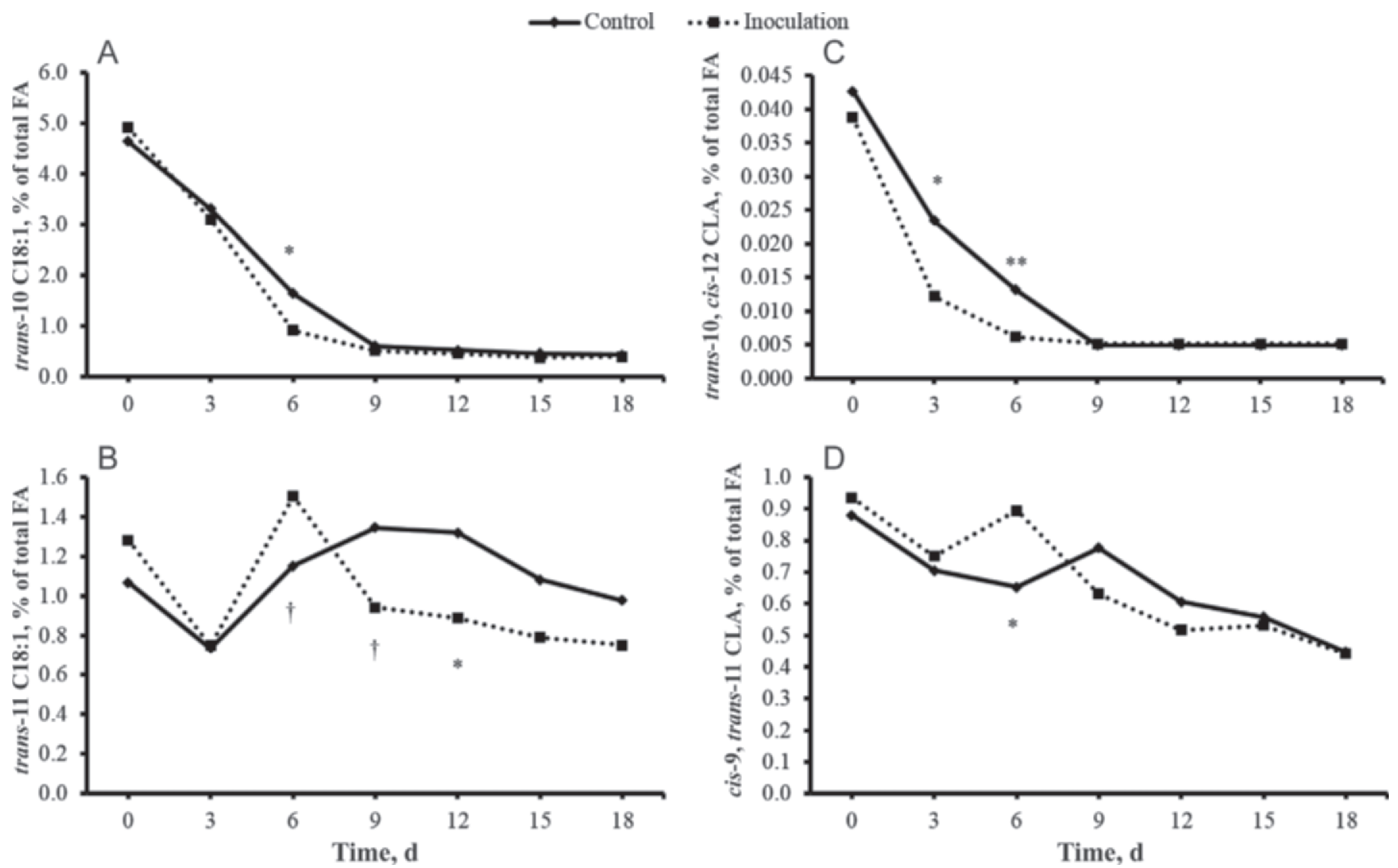

Figure 3. Effect of daily ruminal inoculation (from d 1 to 6 ) with digesta from non-milk fat-depressed cows (inoculation) on the concentration of milk trans FA during recovery from diet-induced milk fat depression compared with the control. (A) trans-10 C18:1; (B) trans-10, cis-12 CLA; (C) trans-11 C18:1; (D) cis-9,trans-11 CLA. Preplanned contrasts tested the difference between the control and inoculation at each time point. ${ }^{*} P<0.01 ;{ }^{*} P<0.05 ; \dagger P<0.1 ; \mathrm{SEM}=0.10,0.08,0.001$, and 0.04 , for trans-10 C18:1, trans-10, cis-12 CLA, trans-11 C18:1, and cis9,trans-11 CLA, respectively.

\section{ACKNOWLEDGMENTS}

The authors gratefully acknowledge the technical assistance of K. Proschold, E. Waumbaugh, and L. W. Rottman-Gredell (Penn State University, University Park PA). Gratitude is also expressed to the Pennsylvania State University Dairy Cattle Research and Education Center and its staff. This project was partially supported by the College of Agriculture Graduate Student Competitive Grant Program at Penn State granted to D. E. Rico and Agriculture and Food Research Initiative Competitive Grant no. 2010-65206-20723 from the USDA National Institute of Food and Agriculture (Washington, DC). Soybean oil was graciously donated by Wenger's Feed Mill Inc. (Rheems, PA).

\section{REFERENCES}

Aikman, P. C., P. H. Henning, D. J. Humphries, and C. H. Horn. 2011. Rumen $\mathrm{pH}$ and fermentation characteristics in dairy cows supplemented with Megasphaera elsdenii NCIMB 41125 in early lactation. J. Dairy Sci. 94:2840-2849.
AOAC International. 2000. Official Methods of Analysis. 17th ed. AOAC International, Gaithersburg, MD.

Bauman, D. E., and J. M. Griinari. 2003. Nutritional regulation of milk fat synthesis. Annu. Rev. Nutr. 23:203-227.

Baumgard, L. H., B. A. Corl, D. A. Dwyer, A. Saebø, and D. E. Bauman. 2000. Identification of the conjugated linoleic acid isomer that inhibits milk fat synthesis. Am. J. Physiol. Regul. Integr. Comp. Physiol. 278:R179-R184.

Borody, T. J., and A. Khoruts. 2012. Fecal microbiota transplantation and emerging applications. Nat. Rev. Gastroenterol. Hepatol. 9:88-96.

Chiquette, J., M. J. Allison, and M. A. Rasmussen. 2008. Prevotella bryantii $25 \mathrm{~A}$ used as a probiotic in early-lactation dairy cows: Effect on ruminal fermentation characteristics, milk production, and milk composition. J. Dairy Sci. 91:3536-3543.

Cole, N. A. 1991. Effects of animal-to-animal exchange of ruminal contents on the feed intake and ruminal characteristics of fed and fasted lambs. J. Anim. Sci. 69:1795-1803.

Francisco, C. C., C. S. Chamberlain, D. N. Waldner, R. P. Wettemann, and L. J. Spicer. 2002. Propionibacteria fed to dairy cows: Effects on energy balance, plasma metabolites and hormones, and reproduction. J. Dairy Sci. 85:1738-1751.

Fuentes, M. C., S. Calsamiglia, P. W. Cardozo, and B. Vlaeminck. 2009. Effect of $\mathrm{pH}$ and level of concentrate in the diet on the production of biohydrogenation intermediates in a dual-flow continuous culture. J. Dairy Sci. 92:4456-4466.

Hall, M. B. 2009. Determination of starch, including maltooligosaccharides, in animal feeds: Comparison of methods and a meth- 
od recommended for AOAC collaborative study. J. AOAC Int. 92:42-49.

Harvatine, K. J., and M. S. Allen. 2006. Effects of fatty acid supplements on feed intake, and feeding and chewing behavior of lactating dairy cows. J. Dairy Sci. 89:1104-1112.

Harvatine, K. J., Y. R. Boisclair, and D. E. Bauman. 2009. Recent advances in the regulation of milk fat synthesis. Animal 3:40-54.

Jenkins, T. C., R. J. Wallace, P. J. Moate, and E. E. Mosley. 2008. Board-Invited Review: Recent advances in biohydrogenation of unsaturated fatty acids within the rumen microbial ecosystem. J. Anim. Sci. 86:397-412.

Oba, M., and M. S. Allen. 2003. Effects of corn grain conservation method on ruminal digestion kinetics for lactating dairy cows at two dietary starch concentrations. J. Dairy Sci. 86:184-194.

Perfield, J. W., II, P. Delmonte, A. L. Lock, M. P. Yurawecz, and D. E. Bauman. 2006. Trans-10,trans-12 conjugated linoleic acid does not affect milk fat yield but reduces $\Delta^{9}$-desaturase index in dairy cows. J. Dairy Sci. 89:2559-2566.

Rico, D. E., and K. J. Harvatine. 2013. Induction of and recovery from milk fat depression occurs progressively in dairy cows switched between diets that differ in fiber and oil concentration. J. Dairy Sci. 96:6621-6630.

Saarisalo, E. M., A. A. Odenyo, and P. O. Osuji. 1999. Inoculation with adapted microbes versus addition of polyethylene glycol as methods to alleviate toxicity of Acacia angustissima leaves in sheep. J. Agric. Sci. 133:445-454.

Satter, L. D., and A. N. Bringe. 1969. Effect of abrupt ration changes on milk and blood components. J. Dairy Sci. 52:1776-1780.

Sukhija, P. S., and D. L. Palmquist. 1988. Rapid method for determination of total fatty acid content and composition of feedstuffs and feces. J. Agric. Food Chem. 36:1202-1206.

Tajima, K., R. I. Aminov, T. Nagamine, H. Matsui, M. Nakamura, and Y. Benno. 2001. Diet-dependent shifts in the bacterial population of the rumen revealed with real-time PCR. Appl. Environ. Microbiol. 67:2766-2774.

Van Soest, P. J., J. B. Robertson, and B. A. Lewis. 1991. Methods for dietary fiber, neutral detergent fiber, and nonstarch polysaccharides in relation to animal nutrition. J. Dairy Sci. 74:3583-3597.

Weimer, P. J., D. M. Stevenson, H. C. Mantovani, and S. L. Man. 2010a. Host specificity of the ruminal bacterial community in the dairy cow following near-total exchange of ruminal contents. J. Dairy Sci. 93:5902-5912.

Weimer, P. J., D. M. Stevenson, and D. R. Mertens. 2010b. Shifts in bacterial community composition in the rumen of lactating dairy cows under milk fat-depressing conditions. J. Dairy Sci. 93:265278. 